\title{
Investigation of Status Quo of Dietary Behavior in Patients with Inflammatory Bowel Disease
}

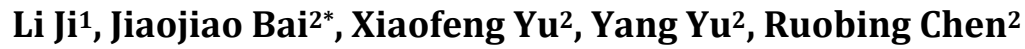 \\ ${ }^{1}$ School of Nursing, Fudan University, Shanghai, China \\ ${ }^{2}$ Huadong Hospital Affiliated to Fudan University, Shanghai, China \\ Email: 13211170012@fudan.edu.cn, "bjj163163@163.com
}

Received 15 March 2016; accepted 15 May 2016; published 18 May 2016

Copyright (C) 2016 by authors and Scientific Research Publishing Inc.

This work is licensed under the Creative Commons Attribution International License (CC BY). http://creativecommons.org/licenses/by/4.0/

(c) (i) Open Access

\begin{abstract}
Objective: To investigate the status quo of dietary behavior of patients with inflammatory bowel disease (IBD) and analyze its influence factors. Methods: All patients $(n=104)$ who went to the department of gastroenterology of Hua Dong Hospital were recruited. Dietary behavior of patients was investigated by a questionnaire self-designed while the nutritional status was evaluated using the Patient-generated Subjective Global Assessment (PG-SGA). Results: Among 104 cases with IBD, the numbers of well dietary belief were 58 cases $(55.8 \%)$ and the poor were 46 cases $(45.2 \%)$. The good eating habits were 33 cases $(31.7 \%)$, the general were 25 cases $(24.0 \%)$ and the poor were $46(44.2 \%)$. The adequate intakes of carbohydrate, protein and fat were separately 36 cases (34.6\%), 25 cases $(24.0 \%)$ and 33 cases $(31.7 \%)$ while the inadequate intakes were separately 68 cases $(65.4 \%), 79$ cases $(76.0 \%)$ and 71 cases $(68.3 \%)$. Sex, culture degree and duration were influence factors of the dietary belief $(P<0.05)$. Conclusion: The problems in dietary behavior are not optimistic. Most patients with IBD are with poor dietary belief and eating habits while the intake of carbohydrate, protein and fat is insufficient although the choice of food is reasonable. And majority of patients were combined with malnutrition. Education of the dietary knowledge about IBD should be strengthened, especially for patients who are female, short-term duration and lower culture degree.
\end{abstract}

\section{Keywords}

Inflammatory Bowel Disease, Dietary Behavior, Influence Factor

\footnotetext{
${ }^{*}$ Corresponding author.
}

How to cite this paper: Ji, L., Bai, J.J., Yu, X.F., Yu, Y. and Chen, R.B. (2016) Investigation of Status Quo of Dietary Behavior in Patients with Inflammatory Bowel Disease. Open Journal of Gastroenterology, 6, 136-145. 


\section{Introduction}

Inflammatory bowel diseases (IBD), including ulcerative colitis (UC) and Crohn' disease (CD), are chronic relapsing intestinal inflammatory diseases, listed as the world refractory disease by World Health Organization (WHO). According to a report in China, the number of patients with IBD in recent 5 years was eight times as that in the same period in the 1990s, among which, the incidences of UC and CD were 11.6/100,000 and 1.4/100,000 [1]. Dietary behavior mainly includes dietary belief, eating habits and dietary pattern and can guarantee nutrition status of patients. However, improper behavior could be harmful to IBD. On the one hand, it could lead to nutrition related diseases, such as diabetic mellitus, cardiovascular, intestinal inflammatory and so on. Jingfan $\mathrm{Gu}$ [2] suggested poor eating habits, like disorderly eating, could result in intestinal diseases through damaging the gastrointestinal mucosa and destroying the protective barrier of gastrointestinal tract. Hou [3] pointed out that dietary behavior was closely related to the occurrence and recurrence of IBD. Zallot [4] investigated the dietary belief and behavior of 224 cases with IBD and found that IBD had something with the kind and the intake of food. One the other hand, improper dietary behavior could cause malnutrition to trigger or deprave symptoms of IBD. It was reported that patients with IBD were usually combined with malnutrition of which the incidence was up to 85\% [5] [6]. Malnutrition was associated with clinical outcomes of IBD by decreasing immunity and injuring intestinal mucosal barrier and so on [7]. Norman [8] suggested that malnutrition could bring about depression and anxiety with patients aggravating IBD. Therefore, it is necessary to manage dietary behavior of patients with IBD. Our study aims to investigate the eating behavior of patients with IBD hoping to provide the evidence for making individualized dietary therapy.

\section{Methodology}

\subsection{Participants}

Participants in this study were recruited from a random of patients diagnosed with IBD between January and December 2015 and presented to the department of gastroenterology of Hua Dong Hospital Affiliated to Fudan University at Shanghai, China. The inclusion criteria were patients with UC or CD diagnosed according to IBD diagnostic criteria recommended by Chinese Society of Gastroenterology in 2008 and the duration was above 1 year.

Approval for this study was obtained from Fudan University ethics and all patients provided their signed informed consent of participation. A total of 104 patients matched the inclusion criteria.

\subsection{Assessment}

\subsubsection{Demographic Questionnaire}

The questionnaire mainly included the patients' general information such as age, sex, disease type, duration and so on.

\subsubsection{Questionnaire of Dietary Behavior}

This questionnaire was self-designed divided into 3 aspects, as following: 1) Dietary belief which includes the relationship between dietary and IBD, tie-in diet and importance of diet therapy proposed by doctors. Every item was scored by Likert Scale. The total scores were between 3 and 15 points. The more the scores were, the better the dietary belief was. It could be divided into three groups bases on the value of $70 \%, 80 \%$ and $90 \%$ of the highest score, as following: 3 - 12, weak dietary belief; 13, the general; and 14 or above, the well. 2) Eating habits consisting of eating times per day, regularity, eating outside, food flavor, cooking methods, oil, nutrition supplement and selections of snacks, seafood, spicy food, pickled food, cold food, coffee, beverage, strong tea, drinking and smoking. Total scores were between 17 and 85 points. It was divided into three groups depending on the value of $70 \%, 80 \%$ and $90 \%$ of the highest score, as: 17 - 68, the poor eating habits; 69 - 76, the general; and 77 or above, the good. 3) Dietary pattern including the intake of carbohydrate food, protein food, fat food, fiber food and nutritional supplements. It was assessed by 24h Dietary Recall. According to Chinese expert consensus on nutrition support treatment about IBD, daily intake of total energy should be up to $25-30 \mathrm{kcal} / \mathrm{kg}$ every day, the intake of protein every day should be $1.0-1.5 \mathrm{~g} / \mathrm{kg}$ and the energy from fat should be account for $30 \%-50 \%$ of total energy. If the daily actual intake of the carbohydrate, protein and fat is equal to or beyond that recommended, it separately suggests that the intake is enough. If not, it suggests the intake is inadequate. 
The content validity of the questionnaire was 0.85 and the retest reliability was 0.90 .

\subsubsection{Patient-Generated Subjective Global Assessment (PG-SGA)}

The tool was simple and effective with high sensitivity and specificity. It could be not only used for gastrointestinal cancer patients, but also applied in chronic diseases. The tool consisted of two parts: 1) patients' self-assessment including weight change, symptoms, dietary intake and activity ability; 2) evaluation of medical personnel including disease diagnosis, age, metabolic stress and physical examination. Total scores were from 0 to 35 points which could be categorized into the following triage ranges: 0 - 3, well nutrition (Grade A); 4 - 8, moderate malnutrition (Grade B); and 9 or above, severely malnutrition (Grade C). Among them, Grad B and Grade C were combined as malnutrition. The too was with good reliability and validity, of which, Cronbach's $\alpha$ was 0.64 , the sensitivity $98 \%$ and the specificity $82 \%$ [9].

All questionnaires were filled in face to face manner. During the survey, participants answered and recorded in the request according to their actual diet after explaining the content of the questionnaires. 110 questionnaires were allocated to patients with IBD. Among them, 6 cases withdrew from the study because of the aggravation of illness. The rate of recovery was $94.5 \%$.

\subsection{Analysis}

All data were processed using SPSS statistics version 19.0. The count data was described as proportion. The measure data was described as mean \pm standard deviation or the maximum, minimum and the median depended on the feature of data. Univariate analysis was analyzed by chi-square test and Fisher exact test, and the multiple-factor analysis was dealt with the logistic regression analysis. In addition, the relationship between dietary belief and eating habits was analyzed by bivariate correlation analysis.

\section{Results}

\subsection{General Information}

Among 104 cases with IBD, the age was between 18 and 85 years old, the median was 56 years old. 31 cases (29.8\%) were 44 years old or below, 34 cases (31.7\%) were between 45 and 59 years old and 39 cases (38.5\%) were 60 years old or above. 39 (37.5\%) cases were junior school or below and 65 cases (62.5\%) were high school or above. Patients with ulcerative colitis (UC) were 77 cases (74.0\%) and those with Crohn's disease were 27 cases (26.0\%). The duration of 66 cases $(51.0 \%)$ was 3 years or below and 38 cases $(49.0 \%)$ was 4 years or above. In addition, the IBD of 46 cases (44.2\%) were at remission and 58cases (55.8\%) were at active stage (Table 1). There was no significant difference between UC and CD in general information $(P>0.05)$.

\section{Table 1. Demographic information of patients with IBD $(n=104)$.}

\begin{tabular}{|c|c|c|c|}
\hline \multicolumn{2}{|c|}{ Categories } & \multirow{2}{*}{$\begin{array}{c}\text { Frequency (n) } \\
62\end{array}$} & \multirow{2}{*}{$\begin{array}{c}\text { Proportion (\%) } \\
59.6\end{array}$} \\
\hline Sex & Male & & \\
\hline & Female & 42 & 40.4 \\
\hline \multirow[t]{3}{*}{ Age } & $18-44$ & 31 & 29.8 \\
\hline & $45-59$ & 33 & 31.7 \\
\hline & $\geq 60$ & 40 & 38.5 \\
\hline \multirow[t]{2}{*}{ Culture degree } & Junior school or below & 39 & 37.5 \\
\hline & High school or above & 65 & 62.5 \\
\hline \multirow[t]{2}{*}{ Duration } & $\leq 3$ & 53 & 51.0 \\
\hline & $\geq 4$ & 51 & 49.0 \\
\hline \multirow[t]{2}{*}{ Type of disease } & UC & 77 & 74.0 \\
\hline & CD & 27 & 26.0 \\
\hline \multirow[t]{2}{*}{ Disease activity index } & Remission & 46 & 44.2 \\
\hline & Activity & 58 & 55.8 \\
\hline
\end{tabular}




\subsection{Situation of Patients' Dietary Behavior}

\subsubsection{Dietary Belief}

Among 104 cases, well dietary belief were 58 cases (55.8\%), the poor were 46 cases (44.2\%)) among which the general were 5 cases (4.8\%) and the weak were 41 cases (39.4\%).

\subsubsection{Eating Habits}

In participants, good eating habits were 33 cases (31.7\%), the general were 25 cases (24.0\%) and the poor were $46(44.2 \%)$.

\subsubsection{Dietary Pattern}

The adequate intake of carbohydrate, protein and fat were separately36 cases (34.6\%), 25 cases $(24.0 \%)$ and 33 cases (31.7\%) while the deficiency intake were 68 cases $(65.4 \%), 79$ cases $(76.0 \%)$ and 71 cases $(68.3 \%)$. The definite situation of dietary intake was shown in Table 2.

\subsubsection{Relationship of Dietary Belief, Eating Habits and Dietary Pattern}

According to Pearson chi-square test and Fisher's exact test, dietary belief had something with eating habits while eating habits could affect dietary pattern $(P<0.05)$ (Table 3, Table 4). It suggested that the score of dietary belief had positive relation to that of eating habits based on bivariate correlation analysis $(r=0.341, P<$ 0.05) (Table 5).

Table 2. Dietary intake situation of patients with IBD $(n=104)$.

\begin{tabular}{|c|c|c|c|c|c|c|}
\hline \multirow{2}{*}{ Categories } & \multirow{2}{*}{ Contents } & \multicolumn{5}{|c|}{ Dietary intake frequency } \\
\hline & & Always & Often & Sometime & Occasionally & Never \\
\hline \multirow[t]{4}{*}{ Carbohydrate } & Rice & $46(44.2)$ & $44(42.3)$ & $12(11.5)$ & $2(1.9)$ & $0(0.0)$ \\
\hline & Wheat & $6(5.8)$ & $34(32.7)$ & 35 (33.7) & $26(25.0)$ & $3(2.9)$ \\
\hline & Corn & $0(0.0)$ & $5(4.8)$ & $12(11.5)$ & $60(57.7)$ & $27(26.0)$ \\
\hline & Starchy & $11.0)$ & $18(17.3)$ & 35 (33.7) & $26(25.0)$ & $24(23.1)$ \\
\hline \multirow[t]{7}{*}{ Protein } & Milk and products & $3(2.9)$ & $10(9.6)$ & $12(11.5)$ & $15(14.4)$ & $64(61.5)$ \\
\hline & Beans and products & $14(13.5)$ & $36(34.6)$ & 17 (16.3) & $25(24.0)$ & $12(11.5)$ \\
\hline & Eggs & $21(20.2)$ & $47(45.2)$ & 17 (16.3) & $18(17.3)$ & $1(1.0)$ \\
\hline & Red meat & $13(12.5)$ & 33 (31.7) & $22(21.2)$ & $28(26.9)$ & $8(7.7)$ \\
\hline & Poultry meat & $12(11.5)$ & $42(40.4)$ & $26(25.0)$ & $14(13.5)$ & $10(9.6)$ \\
\hline & Fish & 14 (13.5) & $50(48.1)$ & 17 (16.3) & $10(9.6)$ & $13(12.5)$ \\
\hline & River shrimp and crab & $1(1.0)$ & 19 (18.3) & $21(20.2)$ & 28 (26.9) & $35(33.7)$ \\
\hline \multirow[t]{2}{*}{ Fat } & Visceral food & $0(0.0)$ & $9(8.7)$ & $24(23.1)$ & $45(43.3)$ & $26(25.0)$ \\
\hline & Greasiness & $0(0.0)$ & $4(3.8)$ & 17 (16.3) & $58(55.8)$ & $25(24.0)$ \\
\hline \multirow[t]{2}{*}{ Fiber } & Coarse grain & $4(3.8)$ & $12(11.5)$ & $23(22.1)$ & $31(29.8)$ & $34(32.7)$ \\
\hline & Fruit and vegetables & $4(3.8)$ & $25(24.0)$ & 18 (17.3) & $29(27.9)$ & $28(26.9)$ \\
\hline Supplement & Vitamins and trace elements & $0(0.0)$ & $13(12.5)$ & $16(15.4)$ & $4(3.8)$ & $71(68.3)$ \\
\hline
\end{tabular}

Table 3. Compared dietary belief and eating habits $(n=104)$.

\begin{tabular}{|c|c|c|c|c|c|c|c|}
\hline \multirow{2}{*}{\multicolumn{2}{|c|}{ Categories }} & \multirow{2}{*}{ Total } & \multicolumn{3}{|c|}{ Eating habits } & \multirow{2}{*}{$\chi^{2}$} & \multirow{2}{*}{$P$} \\
\hline & & & Good & General & Poor & & \\
\hline \multirow[t]{2}{*}{ Dietary belief } & Well & 58 & 26 & 14 & 18 & 12.252 & $0.002^{* *}$ \\
\hline & Poor & 46 & 7 & 11 & 28 & & \\
\hline \multicolumn{2}{|c|}{ Total } & 104 & 33 & 25 & 46 & & \\
\hline
\end{tabular}

$$
* * P<0.01 \text {. }
$$


Table 4. Compared eating habit and dietary pattern $(n=104)$.

\begin{tabular}{|c|c|c|c|c|c|c|}
\hline \multirow{2}{*}{ Categories } & \multicolumn{2}{|c|}{ Carbohydrate } & \multicolumn{2}{|c|}{ Protein } & \multicolumn{2}{|c|}{ Fat } \\
\hline & Adequate & Deficiency & Adequate & Deficiency & Adequate & Deficiency \\
\hline \multicolumn{7}{|l|}{ Eating habits } \\
\hline Poor & 16 & 30 & 15 & 31 & 27 & 19 \\
\hline General & 12 & 13 & 9 & 16 & 5 & 20 \\
\hline Good & 8 & 25 & 1 & 32 & 1 & 32 \\
\hline$\chi^{2}$ & \multicolumn{2}{|c|}{3.548} & \multicolumn{2}{|c|}{11.785} & \multicolumn{2}{|c|}{29.577} \\
\hline$P$ & \multicolumn{2}{|c|}{0.170} & \multicolumn{2}{|c|}{$0.003 * *$} & \multicolumn{2}{|c|}{$0.000 * *$} \\
\hline
\end{tabular}

${ }^{* *} P<0.01$.

Table 5. Correlation analysis between the score of dietary belief and eating habits.

\begin{tabular}{ccc}
\hline Variable & $r$ & $p$ \\
\hline Dietary belief & 0.341 & $0.000^{* *}$ \\
\hline
\end{tabular}

${ }^{* *} P<0.01$.

\subsection{Univariate Analysis of Dietary Behavior}

\subsubsection{Comparing Dietary Belief of Different Patients}

According to Pearson chi-square test and Fisher's exact test, the difference of dietary belief in patients in different duration of IBD was significant $(P<0.05)$ (Table 6).

\subsubsection{Comparing Eating Habits of Different Patients}

According to Pearson chi-square test and Fisher's exact test, the culture degree and duration of IBD were related to eating habits $(P<0.05)$ (Table 7$)$.

\subsubsection{Comparing Dietary Pattern of Different Patients}

According to Pearson chi-square test and Fisher's exact test, the dietary pattern distributed in the different sex, culture degree and duration of IBD was significantly different $(P<0.05)$ (Table 8).

\subsection{Multiple-Factor Analysis of Dietary Behavior}

\subsubsection{Dietary Belief}

According to logistic regression analysis, the duration of IBD is the independent factor of dietary belief (Table 9).

\subsubsection{Eating Habits}

The results suggest that the culture degree and duration are independent factors of eating habits (Table 10).

\subsubsection{Dietary Pattern}

According to the logistic regression analysis, duration of IBD can influence the intake of protein while the sex and the duration affect the intake of fat (Table 11).

\subsection{Nutrition Status}

Based on PG-SGA, there were 25 cases with Grade A accounted for 24.1\%, 56 cases with Grade B for 53.8\% and 23 cases with Grade C for $22.1 \%$.

\section{Discussion}

\subsection{Dietary Behavior of Patients with IBD}

\subsubsection{Dietary Belief}

Whether you own correct dietary belief decides the efforts and persistence of behabior during diet management. 
Table 6. Dietary belief situation of different patients with IBD $(n=104)$.

\begin{tabular}{|c|c|c|c|c|c|}
\hline \multirow{2}{*}{\multicolumn{2}{|c|}{ Categories }} & \multicolumn{2}{|c|}{ Dietary belief } & \multirow{2}{*}{$\chi^{2}$} & \multirow{2}{*}{$P$} \\
\hline & & Poor & Well & & \\
\hline \multirow[t]{2}{*}{ Sex } & Male & 26 & 36 & \multirow{2}{*}{0.328} & \multirow{2}{*}{0.688} \\
\hline & Female & 20 & 22 & & \\
\hline \multirow[t]{3}{*}{ Age } & $18-44$ & 18 & 13 & \multirow{3}{*}{3.453} & \multirow{3}{*}{0.178} \\
\hline & $45-59$ & 13 & 20 & & \\
\hline & $\geq 60$ & 15 & 25 & & \\
\hline \multirow[t]{2}{*}{ Culture degree } & Junior school or below & 14 & 25 & \multirow{2}{*}{1.757} & \multirow{2}{*}{0.223} \\
\hline & High school or above & 32 & 33 & & \\
\hline \multirow[t]{2}{*}{ Type of disease } & UC & 32 & 45 & \multirow{2}{*}{0.859} & \multirow{2}{*}{0.377} \\
\hline & $\mathrm{CD}$ & 14 & 13 & & \\
\hline \multirow[t]{2}{*}{ Duration } & $\leq 3$ & 30 & 23 & \multirow{2}{*}{6.708} & \multirow{2}{*}{$0.010^{*}$} \\
\hline & $\geq 4$ & 16 & 35 & & \\
\hline \multirow[t]{2}{*}{ Disease activity index } & Remission & 22 & 23 & \multirow{2}{*}{0.698} & \multirow{2}{*}{0.404} \\
\hline & Activity & 24 & 35 & & \\
\hline
\end{tabular}

${ }^{*} P<0.05$.

Table 7. Eating habits of different patients with IBD $(n=104)$.

\begin{tabular}{|c|c|c|c|c|c|c|}
\hline \multirow{2}{*}{\multicolumn{2}{|c|}{ Categories }} & \multicolumn{3}{|c|}{ Eating habits } & \multirow{2}{*}{$\chi^{2}$} & \multirow{2}{*}{$P$} \\
\hline & & Poor & General & Good & & \\
\hline \multirow[t]{2}{*}{ Sex } & Male & 30 & 15 & 17 & 1.501 & 0.472 \\
\hline & Female & 16 & 10 & 16 & & \\
\hline \multirow[t]{3}{*}{ Age } & $18-44$ & 16 & 9 & 6 & 3.547 & 0.471 \\
\hline & $45-59$ & 14 & 8 & 11 & & \\
\hline & $\geq 60$ & 16 & 8 & 16 & & \\
\hline \multirow[t]{2}{*}{ Culture degree } & Junior school or below & 11 & 8 & 20 & 11.463 & $0.003^{* *}$ \\
\hline & High school or above & 35 & 17 & 13 & & \\
\hline \multirow[t]{2}{*}{ Type of disease } & UC & 32 & 20 & 25 & 0.992 & 0.609 \\
\hline & $\mathrm{CD}$ & 14 & 5 & 8 & & \\
\hline \multirow[t]{2}{*}{ Duration } & $\leq 3$ & 35 & 11 & 7 & 29.791 & $0.000^{* *}$ \\
\hline & $\geq 4$ & 11 & 14 & 26 & & \\
\hline \multirow{2}{*}{ Disease activity index } & Remission & 22 & 10 & 13 & 0.700 & 0.705 \\
\hline & Activity & 24 & 15 & 20 & & \\
\hline
\end{tabular}

${ }^{* *} P<0.01$

In this study, $44.2 \%$ of participants were with weak dietary belief, mainly reflected in that they thought it had nothing between diet and IBD, ignored the collocation of dietary nutrition or thought there was no necessary to obey doctors' dietary therapy. This reflected that patients could not understand the relationship between diet and IBD. Ying Zhu [10] pointed that above $60 \%$ of patients with IBD were lack of related dietary knowledge. It suggested that the health education should be strengthened to improve patients' dietary belief. Malik [11] pointed out that an internet forum about self-help management on IBD promoted the level of knowledge and improve and further to improve dietary belief through communicating with patients timely and effectively. 
Table 8. Dietary pattern of different patients with IBD $(\mathrm{n}=104)$.

\begin{tabular}{|c|c|c|c|c|c|c|}
\hline \multirow{2}{*}{ Categories } & \multicolumn{2}{|c|}{ Carbohydrate } & \multicolumn{2}{|c|}{ Protein } & \multicolumn{2}{|c|}{ Fat } \\
\hline & Deficiency & Adequate & Deficiency & Adequate & Deficiency & Adequate \\
\hline \multicolumn{7}{|l|}{ Sex } \\
\hline Male & 41 & 21 & 46 & 16 & 37 & $25^{*}$ \\
\hline Female & 27 & 15 & 33 & 9 & 34 & 8 \\
\hline \multicolumn{7}{|l|}{ Age } \\
\hline $18-44$ & 18 & $13^{*}$ & 22 & 9 & 22 & 9 \\
\hline $45-59$ & 18 & 15 & 26 & 7 & 20 & 13 \\
\hline$\geq 60$ & 32 & 8 & 31 & 9 & 29 & 11 \\
\hline \multicolumn{7}{|l|}{ Culture degree } \\
\hline junior school or below & 31 & $8 *$ & 32 & 7 & 30 & 9 \\
\hline high school or above & 37 & 28 & 47 & 18 & 41 & 24 \\
\hline \multicolumn{7}{|l|}{ Type of disease } \\
\hline UC & 50 & 27 & 58 & 19 & 52 & 25 \\
\hline CD & 18 & 9 & 21 & 6 & 19 & 8 \\
\hline \multicolumn{7}{|l|}{ Duration } \\
\hline$\leq 3$ & 35 & 18 & 34 & $19 * *$ & 31 & $22 *$ \\
\hline$\geq 4$ & 33 & 18 & 45 & 6 & 40 & 11 \\
\hline \multicolumn{7}{|l|}{ Disease activity index } \\
\hline Remission & 28 & 17 & 37 & 8 & 30 & 15 \\
\hline Activity & 40 & 19 & 42 & 17 & 41 & 18 \\
\hline
\end{tabular}

$* P<0.05,{ }^{* *} P<0.01$.

Table 9. Multiple-factor analysis of dietary belief.

\begin{tabular}{ccccccc}
\hline Variable & $B$ & S.E & Wals & $P$ & Exp $(B)$ & $95 \% C I$ \\
\hline Duration & 1.048 & 0.410 & 6.548 & $0.011^{*}$ & 2.853 & {$[1.278,6.370]$} \\
\hline
\end{tabular}

$* P<0.05$.

Table 10. Multiple-factor analysis of eating habits.

\begin{tabular}{cccccc}
\hline Variables & $B$ & S.E & Wals & $P$ & $95 \%$ CI \\
\hline Culture degree & 1.263 & 0.416 & 9.234 & $0.002^{* *}$ & {$[0.448,2.078]$} \\
Duration & 1.947 & 0.418 & 21.670 & $0.000^{* *}$ & {$[2.767,1.127]$} \\
\hline
\end{tabular}

${ }^{* *} P<0.01$

Table 11. Multiple-factor analysis of dietary pattern.

\begin{tabular}{|c|c|c|c|c|c|c|c|}
\hline Dietary pattern & Variables & $B$ & S.E & Wals & $P$ & $\operatorname{Exp}(B)$ & $95 \% C I$ \\
\hline \multirow{2}{*}{ Carbohydrate } & Age & -0.351 & 0.272 & 1.665 & 0.197 & 0.704 & {$[0.413,1.200]$} \\
\hline & Culture degree & 0.873 & 0.496 & 3.102 & 0.078 & 2.394 & {$[0.906,6.325]$} \\
\hline Protein & Duration & -1.433 & 0.521 & 7.579 & $0.006^{* *}$ & 0.239 & {$[0.086,0.662]$} \\
\hline \multirow{2}{*}{ Fat } & Sex & -1.089 & 0.482 & 5.108 & $0.024^{*}$ & 0.336 & {$[0.131,0.865]$} \\
\hline & Duration & -0.983 & 0.453 & 4.719 & $0.030^{*}$ & 0.374 & {$[0.154,0.908]$} \\
\hline
\end{tabular}

$* P<0.05, * * P<0.01$. 


\subsubsection{Eating Habits}

Eating habits refers to the preference for food built for a long time in daily life. This study suggested that there were only $31.7 \%$ of participants with good eating habits. Because majority of participants ate irregularly or outside, drunk, smoked or ate snacks, seafood and so on. These may be related to the lack of knowledge about diet or poor ability of self-management on the disease [12]. Whether the eating habits were good or not could directly affect dietary pattern. Christopher [13] pointed that it could aggravate symptoms of IBD if eating spicy or fried food too much. Spicy food could cause the recurrence of IBD resulting from irritating the intestinal wall to be congestive edema and cause the spasm of smooth muscle while sea food would aggravate IBD for some special protein in it which could act as antigen to result in allergic response [13]. It is essential for patients to develop good eating habits to control IBD. Yunxian Zhou [14] suggested that dietary diary could find bad eating habits, like $5.7 \%$ of subjects ate irregularly or ignored breakfast, and could provide the basis for individual self-management.

\subsubsection{Dietary Pattern}

Reasonable dietary pattern, mainly including the intake of food and the proportion of dietary nutrients, is one of four cornerstones to guarantee health. This study showed that even if the selection of food containing carbohydrate, protein and fat was reasonable, the amount of dietary intake was inadequate. In 104 cases, the proportion of the deficient intake of carbohydrate, protein and fat were separately $65.4 \%, 76.0 \%$ and $68.3 \%$, among which the insufficient intake of protein was rather obvious. These may be caused by excessive limitation of eating in case of the recurrence of IBD. Patients with IBD easily developed malnutrition due to unreasonable dietary pattern together with intestinal inflammation. This study suggested that patients should pay more attention on the intake of diet and adjust dietary therapy properly. If necessary, nutritional supplements or intestinal nutrition can be selected to improve nutrition status and promote the recovery of the disease.

\subsubsection{The Relationship between Dietary Belief, Eating Habits and Dietary Pattern}

This study suggested that scores of dietary belief and eating habits had positive correlation $(P<0.05)$. Xianhong Han [15] found that patients with well dietary belief often had good eating habits. When someone aware that the behavior is beneficial to treat disease, he or she can actively adjust their diet and develop good eating habits. Dietary belief plays an important role in the process of self-management [16]. Cuiping Cheng [17] found dietary health belief could help control the intake of sweet, fried and so on through surveying the dietary behavior of 992 cases. In addition, eating habits could affect dietary pattern, especially the intake of protein and fat $(P<$ 0.05). Patients with good eating habits tend to be more concerned about dietary which may aggravate IBD to control the disease. But among participants with good eating habits, the adequate intake of protein was only accounted for $3.0 \%$ while the fat was 3.0\%. This may be resulted from strictly restricting intake of food such protein and fatty food for fear that improper diet triggering the recurrence of IBD. Jowett [18] [19] pointed that excessive intake of protein and fat could increase the burden of gastrointestinal and induce inflammation to aggravate IBD. However, eating too less could result in malnutrition likely further to reduce immunity and even prevent intestinal mucosal from healing. So, the management measures should be applied into adjust dietary pattern actually, including the selection of food and the intake of diet.

\subsection{Influence Factors of Dietary Behavior in Patients with IBD}

\subsubsection{Duration}

IBD is a recurrent chronic disease. This study suggested duration was an independent factor of dietary behavior affecting dietary belief and eating habits $(P<0.05)$. The longer the duration was, the better the dietary belief and eating habits were. The reasons included that: 1 ) patients with longer duration relatively accepted more guidance and attained more knowledge about diet; 2) with the extension of duration, patients had much experience in managing their dietary behavior to control disease. It suggests that patients with short-term duration should be paid more attention. If necessary, discharge nursing service can be provided [20].

\subsubsection{Level of Education}

This study showed that the level of education was an independent factor for eating habits $(P<0.05)$, which was consistent with the study of Ying Zhu [10]. Patients with high level of education usually are with good eating 
habits. The reasons may be that people with higher degree of education not only owned good knowledge and paid much attention on their health, but also had more access to information of disease, could understand and accept new knowledge easier and were more able to take activity in time. Simple, clear and targeted dietary guidance should be supported, especially for patients with lower level of education, such as giving healthy handbook. Huafen Wang [21] pointed that network interaction education could promote the patients to participate in the management of disease to develop good eating habits.

\subsubsection{Sex}

In this study, the intake of fat in males was more than that in females and sex was an influence factor of dietary pattern $(P<0.05)$. Xiqian Zhu [22] put forward that the intake of diet in males was normally more than that in females. This reason may be that males need more supplements due to faster metabolism while females easily reduce the consumption of meat to maintain their image or even lose weight [23].

\subsection{Situation of Nutrition}

According to PG-SGA, there were $75.9 \%$ of participants along with malnutrition which was consistent with the result of the research done by Wenying He [24]. The epidemiological studies in China showed that the incidence of malnutrition in patients with IBD was from $75 \%$ to $85 \%$ while that was from $20 \%$ to $85 \%$ in the foreign [25]-[28]. As known, malnutrition could reduce immunity, increase the incidence of complications and decrease the quality of life [29]. This may be caused by insufficient intake, obstacle intestinal absorption, loss of nutrition, excessive consumption of the body and so on, among which insufficient intake was main reason [7] [29]. In addition, the deficient intake of protein was more obvious than carbohydrate and fat. Therefore, it should encourage patients to choice and adjust diet rationally to avoid restricting intake too seriously. In addition, enteral and parenteral nutrition could be accepted timely to improve patients' nutritional status and promote the rehabilitation of IBD.

\section{Conclusion}

There are some problems existing patients with IBD, such as weak diet idea, poor diet habits and deficiency intake of three major nutrients. What is worse, majority of patients are combined with malnutrition. So, it should strengthen the management and health education of diet to develop good dietary behavior meeting the requirement of disease rehabilitation, especially paying attention on those who are female or along with lower level of education degree and short-term duration.

\section{Conflict of Interest}

Authors declare no potential conflicts of interest for this article.

\section{References}

[1] Wang, Y., Ouyang, Q. and Hu, R. (2010) Progression of Inflammatory Bowel Disease in China. Journal of Digestive Diseases, 11, 76-82. http://dx.doi.org/10.1111/j.1751-2980.2010.00421.X

[2] Gu, J., Du, S. and Guo, C. (2009) Xian Dai Lin Chuang Ying Yang Xue. 2. Science Press, Beijing.

[3] Hou, J.K., Lee, D. and Lewis, J. (2014) Diet and Inflammatory Bowel Disease: Review of Patient-Targeted Recommendations. Clinical Gastroenterology and Hepatology, 12, 1592-1600. http://dx.doi.org/10.1016/j.cgh.2013.09.063

[4] Zallot, C., Quilliot, D., Chevaux, J., et al. (2013) Dietary Beliefs and Behavior among Inflammatory Bowel Disease Patients. Inflammatory Bowel Diseases, 19, 66-72. http://dx.doi.org/10.1002/ibd.22965

[5] Massironi, S., Rossi, R.E., Cavalcoli, F.A., et al. (2013) Nutritional Deficiencies in Inflammatory Bowel Disease: Therapeutic Approaches. Clinical Nutrition, 32, 904-910. http://dx.doi.org/10.1016/j.clnu.2013.03.020

[6] Vagianos, K., Bector, S., McConnell, J., et al. (2007) Nutrition Assessment of Patients with Inflammatory Bowel Disease. Journal of Parenteral and Enteral Nutrition, 31, 311-319. http://dx.doi.org/10.1177/0148607107031004311

[7] Lucendo, A.J. and De Rezende, L.C. (2009) Importance of Nutrition in Inflammatory Bowel Disease. World Journal of Gastroenterology, 15, 2081-2088. http://dx.doi.org/10.3748/wjg.15.2081

[8] Norman, K., Kirchner, H., Lochs, H., et al. (2006) Malnutrition Affects Quality of Life in Gastroenterology Patients. World Journal of Gastroenterology, 12, 3380-3385. http://dx.doi.org/10.3748/wjg.v12.i21.3385 
[9] Isenring, E., Bauer, J. and Capra, S. (2003) The Scored Patient-generated Subjective Global Assessment (PG-SGA) and Its Association with Quality of Life in Ambulatory Patients Receiving Radiotherapy. European Journal of Clinical Nutrition, 57, 305-309. http://dx.doi.org/10.1038/sj.ejcn.1601552

[10] Zhu, Y., Lin, Z., Ding, X. et al. (2014) Disease-Related Knowledge and Health Information Needs in Patients with Inflammatory Bowel Disease. Chinese Journal of Nursing, 49, 66-70.

[11] Malik, S. and Coulson, N.S. (2011) The Therapeutic Potential of the Internet: Exploring Self-Help Processes in an Internet Forum for Young People with Inflammatory Bowel Disease. Gastroenterology Nursing, 34, 439-448. http://dx.doi.org/10.1097/SGA.0b013e318237a9ba

[12] Song, G.J., Yang, Z.X., Xue, D.M., et al. (2014) Qualitative Research on Formation of Unhealthy Dietary Habits in Type 2 Diabetes Patients. Journal of Nursing Science, 29, 77-78.

[13] Triggs, C.M., Munday, K., Hu, R., et al. (2010) Dietary Factors in Chronic Inflammation: Food Tolerances and Intolerances of a New Zealand Caucasian Crohn's Disease Population. Mutation Research/Fundamental and Molecular Mechanisms of Mutagenesis, 690, 123-138. http://dx.doi.org/10.1016/j.mrfmmm.2010.01.020

[14] Zhou, Y.X. and Ying, L.Y. (2013) Design and Application of Diet Diary to Patients with Inflammatory Bowel Diseases. Journal of Nursing Science, 28, 8-10.

[15] Han, X.H. and Dai, X.J. (2015) Diet Knowledge, Attitude, Practice and Information Needs among Attendants of Ulcerative Colitis. Chinese Journal of Practical Nursing, 31, 300-303.

[16] McDonald-Miszczak, L., Wister, A.V. and Gutman, G.M. (2001) Self-Care among Older Adults: An Analysis of the Objective and Subjective Illness Contexts. Journal of Aging and Health, 13, 120-145. http://dx.doi.org/10.1177/089826430101300106

[17] Cheng, C. (2013) A Study on the Questionnaire and Characteristics of Middle School Students' Diet Health Beliefs. Xinan University, Chongqing.

[18] Jowett, S.L., Seal, C.J., Pearce, M.S., et al. (2004) Influence of Dietary Factors on the Clinical Course of Ulcerative Colitis: A Prospective Cohort Study. Gut, 53, 1479-1484. http://dx.doi.org/10.1136/gut.2003.024828

[19] Shores, D.R., Binion, D.G., Freeman, B.A., et al. (2011) New Insights into the Role of Fatty Acids in the Pathogenesis and Resolution of Inflammatory Bowel Disease. Inflammatory Bowel Diseases, 17, 2192-2204. http://dx.doi.org/10.1002/ibd.21560

[20] Huang, V.W., Reich, K.M. and Fedorak, R.N. (2014) Distance Management of Inflammatory Bowel Disease: Systematic Review and Meta-Analysis. World Journal of Gastroenterology, 20, 829-842. http://dx.doi.org/10.3748/wjg.v20.i3.829

[21] Wang, H.F., Ma, Y., Lv, M.F., et al. (2013) Effect of Network Interaction Education on the Quality of Life in Patients with Inflammatory Bowel Disease. Chinese Journal of Nursing, 48, 163-165.

[22] Zhu, X.Q. (2011) Study on Nutritional Knowledge, Attitude, Behavior of Young Lovers and Single Persons and Effect of Nutritional Peer Education. Shangdong University, Jinan.

[23] Li, J.B. (2013) The Study of the Status and Influencing Factors of Nutrition as Well as Its Countermeasures in Mental Workers. Shangdong University, Jinan.

[24] He, W., Zhang, X., Wei, X., et al. (2010) Subjective Global Assessment in Nutritional Status Evaluation of Patients with Inflammatory Bowel Diseases. Clinical Misdiagnosis \& Mistherapy, 23, 1111-1113.

[25] Han, P.D., Burke, A., Baldassano, R.N., et al. (1999) Nutrition and Inflammatory Bowel Disease. Gastroenterology Clinics of North America, 28, 423-443. http://dx.doi.org/10.1016/S0889-8553(05)70063-7

[26] Cabre, E. and Gassull, M.A. (2001) Nutrition in Inflammatory Bowel Disease: Impact on Disease and Therapy. Current Opinion in Gastroenterology, 17, 342-349. http://dx.doi.org/10.1097/00001574-200107000-00008

[27] Zhang, J., Zhang, D., Liu, S., et al. (2015) The Nutritional Status Evaluation of Patients with Inflammatory Bowel Disease by Mini Nutritional Assessment and Subjective Global Assessment. Journal of Parenteral and Enteral Nutrition, 22, 348-354.

[28] He, W., Zhang, X., Wei, X., et al. (2010) The Nutritional Status Evaluation for the Patients with Inflammatory Bowel Disease by Mini-Nutritional Assessment. Hebei Medical Journal, 32, 2977-2979.

[29] Gerasimidis, K., McGrogan, P. and Edwards, C.A. (2011) The Aetiology and Impact of Malnutrition in Paediatric Inflammatory Bowel Disease. Journal of Human Nutrition and Dietetics, 24, 313-326. http://dx.doi.org/10.1111/j.1365-277X.2011.01171.x 